\title{
PHYSICO-CHEMICAL PROPERTIES OF GLYCOGEN FROM THE RAT LIVER AND MUSGLE
}

\author{
Teruo IWAMASA \\ Department of Pathology, Kumamoto University School of Medicine, \\ Kumamoto (Director: Prof. Tadao Takeuchi) \\ Reveiced for publication July 17, 1972
}

\begin{abstract}
As reported previously $(6,7,8)$, the glycogen particles from the rat liver and muscle appeared as the specific forms of spheroidal branching bodies. The branching structures were more clearly demonstrated in the glycogen particles from the fasted animal and these appearances were different from the aggregated structures. The chemical and physico-chemical properties of glycogens from the rat liver and muscle are demonstrated and discussed in this paper.

1. End group assay of the glycogens and $\beta$-amylase digestion degree suggested that the average chain length of the liver glycogen was longer than the muscle glycogen.

2. The viscosity of glycogen, measured by varing the temperature from $10^{\circ} \mathrm{C}$ to $70^{\circ} \mathrm{C}$, showed the non-aggregated structure of the glycogen particles. 3. The optical rotartory dispersion and circular dichroism spectra of the glycogen were measured using an addition of iodine solution, and only the muscle glycogen showed the Cotton effect.

4. The sedimentation coefficient of the liver glycogen showed the larger $s$ value than the muscle one, and the relationship between $s$ value and concentration of the glycogen was discussed.
\end{abstract}

Recently it has become possible to explore the fine chemical structure of glycogen by using the enzyme system. The regularly rebranched structure originally proposed by Mayer (16) was the one of the existing proposals that could fit the results of exploration of glycogen by using debranching enzymes, and the chemical structure has been generally accepted $(1,5,9,10,12,13)$.

On the other hand, using the electron microscope, the macromolecular structure of glycogen was demonstrated. Drochmans (4) proposed the $\alpha$-particle and $\beta$ particle as its subunit consisting of $\gamma$-element in the structure of glycogen particles and it has been considered that those appearances resulted from protein-bound aggregation as proposed by Lazarrow (11).

Recently, the new observation of glycogen particles was tried using the electron microscope in our laboratory and it was suggested that the glycogen particles have the non-aggregated structure $(6,7)$. The biosynthesis of polysaccharide from

This work was supported by a grant (No. 777079) from the Education Ministry of Japan.

I am indebted to Professor T. Takeuchi for his helpful guidance and Professor G. Matsumura, Department of Physical Chemistry, School of Pharmaceutical Science, Showa University, for his kind suggestions of this work. 
glucose-1-phosphate by the combined actions of muscle phosphorylase and liver branching glycosyltransferase showed the non-aggregated structure of $\alpha$-glucopyranose polymer which had a close resembrance to the liver glycogen $(6,17)$. Up to today, however, the macromolecular structure of glycogen still has been obscure. Thus, this report is concerned with the investigation of the chemical and physico-chemical properties of glycogen extracted from the rat liver and muscle by using a very mild technique.

\section{MATERIALS AND METHODS}

Animals: Male Donryu rats weighing $250-350 \mathrm{~g}$ were used. All the animals were maintained on a regular diet of commercial products.

Preparation of glycogen from the liver and muscle: According to the method used by Barton (2) and Bueding et al. (3). Ten grams of liver and $200 \mathrm{~g}$ of muscle were minced and homogenated respectively for $10 \mathrm{~min}$, at $0^{\circ} \mathrm{C}$ with 5 volumes $(\mathrm{w} / \mathrm{v})$ of $1 \mathrm{mM}$ EDTA solution (8). This homogenate was centrifuged at $10000 \times \mathrm{g}$ for $30 \mathrm{~min}$ and the precipitates were discarded. The supernatant was recentrifuged at $105000 \times \mathrm{g}$ for $60 \mathrm{~min}$. The pellet had two layers. The upper reddish part was discarded and then the lower opaque layer was suspended in distilled water $(0.1 \mathrm{M}$ of the original volumes).

Subsequently, sodium desoxycholate was added to this solution to a final concentration of $1 \%$ and it was centrifuged at $105000 \times \mathrm{g}$ for $60 \mathrm{~min}$. The pellet which was identified as glycogen was extracted with Sevag's procedure (19), and sedimented by $70 \%$ ethanol. The ethanol precipitate was washed 3 times with $50 \%$ ethanol and washed also with ethyl ether. Finally, the glycogne product was dialysed against distilled water. Furthermore, this glycogen was applied to sepharose $4 \mathrm{~B}$ column $(2.5 \times 28 \mathrm{~cm})$. The glycogen was firstly eluted by $0.1 \mathrm{M}$ $\mathrm{NaCl}$ solution. By this procedure, the oligosaccharide and protein, even if any contamination exits, was removed.

Assay of glycogen: 1. Glycogen was assayed spectrophotometrically by the anthrone method (18).

2. Protein concentration in the glycogen product was determined by use of Lowry's method (15).

3. Infra-red spectra of glycogen was measured by the $\mathrm{KBr}$ technique with a Hitachi model EPI-G3 infra-red spectrophotometer.

4. Electron microscopic observation of glycogen was carried out after negative staining with uranyl acetate, as described in the previous reports (68). Photographs were taken at 50000 and 60000 direct magnification.

End group assay of glycogen: End group assay of glycogen was made by periodate oxidation by using the method reported previously (6).

$\beta$-Amylolysis of glycogen: The glycogen product $(5 \mathrm{mg} / \mathrm{ml})$ was incubated at $37^{\circ} \mathrm{C}$ in $50 \mathrm{mM}$ acetate buffer ( $\mathrm{pH} 5.7)$ with (0.5 IU) sweet potato $\beta$-amylase, obtained from Katayama Chemical Co. The degree of digestion was assayed by reducing sugar with Nelson's reagent. The degree of $\beta$-amylolysis was expressed as the percentage conversion of glycogen into maltose.

Comparison of $\beta$-limit dextrin from the liver and muscle glycogen: The incubation mixture described above for $\beta$-amylolysis was heated at $100^{\circ} \mathrm{C}$ for $5 \mathrm{~min}$ to inactivate the 
$\beta$-amylase activity, and it was applied to the sepharose $4 \mathrm{~B}$ column $(2.5 \times 28 \mathrm{~cm})$. A solution of $0.1 \mathrm{M} \mathrm{NaCl}$ was used as the eluent. The fractions $(3 \mathrm{ml})$ were collected and the carbohydrate in each tube was determined by the anthrone method. The measurement of viscosity: The viscosity measurement was made on $5 \%$ aq. solution of liver glycogen in Cannon-Menning Semimicro 50 A 302 viscometer (constant: 0.003844 centistokes/second). In this case, the viscosity related to variation in temperature (from $10^{\circ} \mathrm{C}$ to $70^{\circ} \mathrm{C}$ ) was calculated.

The measurement of the optical rotatory dispersion $(O R D)$ and circular dichroism $(C D)$ waves: These were made by ORD/UV-5 Japan Spectroscopic Co. The concentration of glycogen was $1 \mathrm{mg} / \mathrm{ml}$. To $0.5 \mathrm{ml}$ of this glycogen solution, $0.1 \mathrm{ml}$ of $0.01 \mathrm{~N} \mathrm{I}_{2}$ was added. The ORD and CD measurements were carried out in the cells $0.2 \mathrm{~cm}$ in length.

Analytical ultracentrifugation: All the analytical ultracentrifugation works were carried out in the laboratory of Prof. G. Matsumura on the model UCA-IA Hitachi analytical ultracentrifuge equipped with Schlieren optics. Rotor RA $60 \mathrm{H}$ was used; the single sector cell with a 12-mm was completely filled. All centrifugations were done at $24^{\circ} \mathrm{C}$ at $16880 \mathrm{rpm}$. Photographs were taken at $9 \mathrm{sec}$ exposure for the liver and muscle glycogens. The sedimentation coefficients were evaluated at different glycogen concentrations of $5 \mathrm{mg} / \mathrm{ml}$ and $10 \mathrm{mg} / \mathrm{ml}$ respectively.

\section{RESULTS}

Assay of glycogen: Protein was almost not detectable from the glycogen products. Infra-red spectra waves were illustrated in Fig. 1 and 2. Both glycogens from

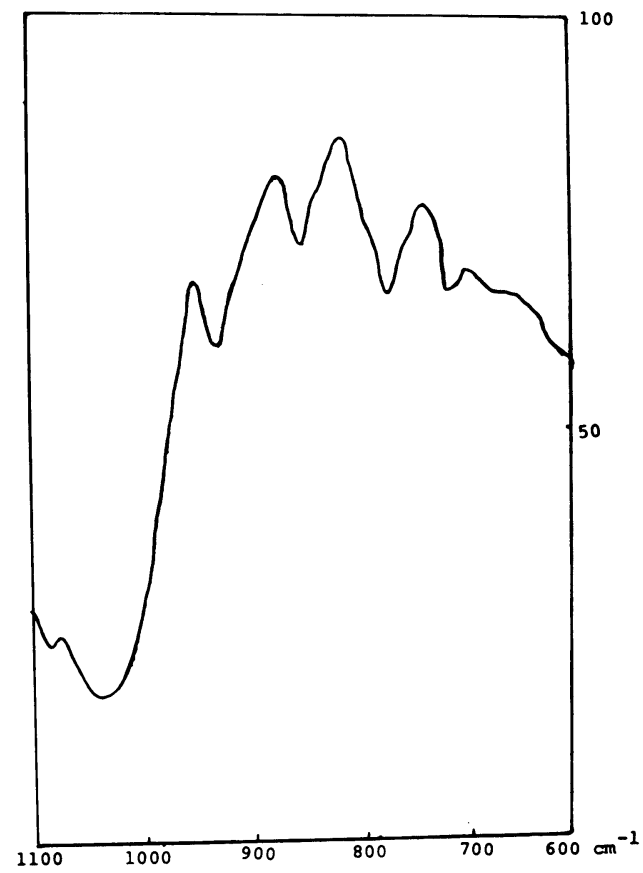

Fig. 1. Infra-red Spectrum of Liver Glycogen

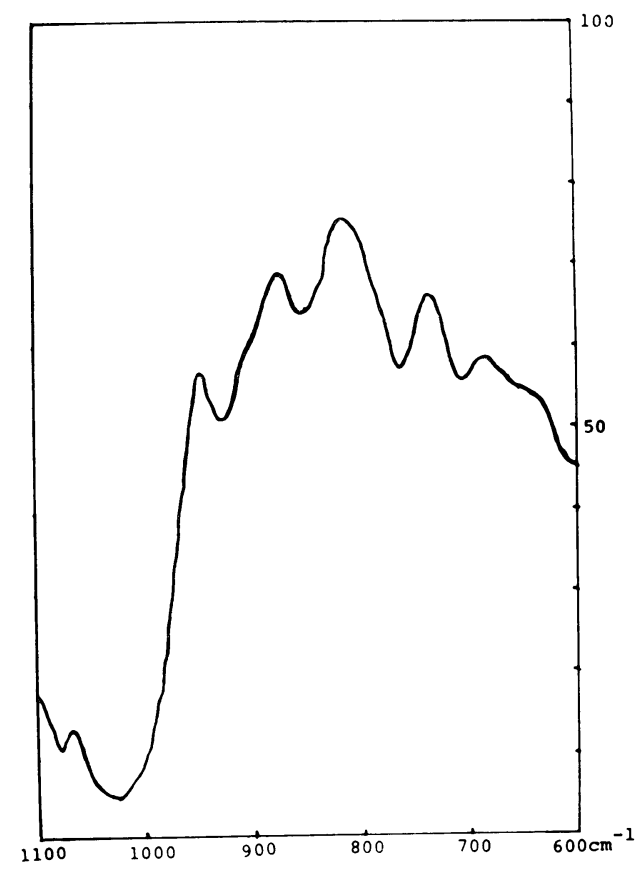

Fig. 2. Infra-red Spectrum of Muscle Glycogen 
the liver and muscle showed the absorptions of type I, type IIa and type III which were specific in the $\alpha$-polysaccharide (6). Electronmicroscopic observation of both glycogens showed the spheroidal branching structure. The liver glycogen appeared as larger branching structure and the muscle glycogen showed the smaller branching bodies. These branching figures of glycogen particles were more clearly demonstrated in the product extracted from the fasted rats than the wellfed rats (Fig. 3.a, b, c and d).

End group assav: By the periodate oxidation, the average chain length of the liver glycogen was calculated as 11.6 and it was 5.6 in the muscle glycogen. The degree of branching of the liver and muscle glycogen were 8.6 and 17.8
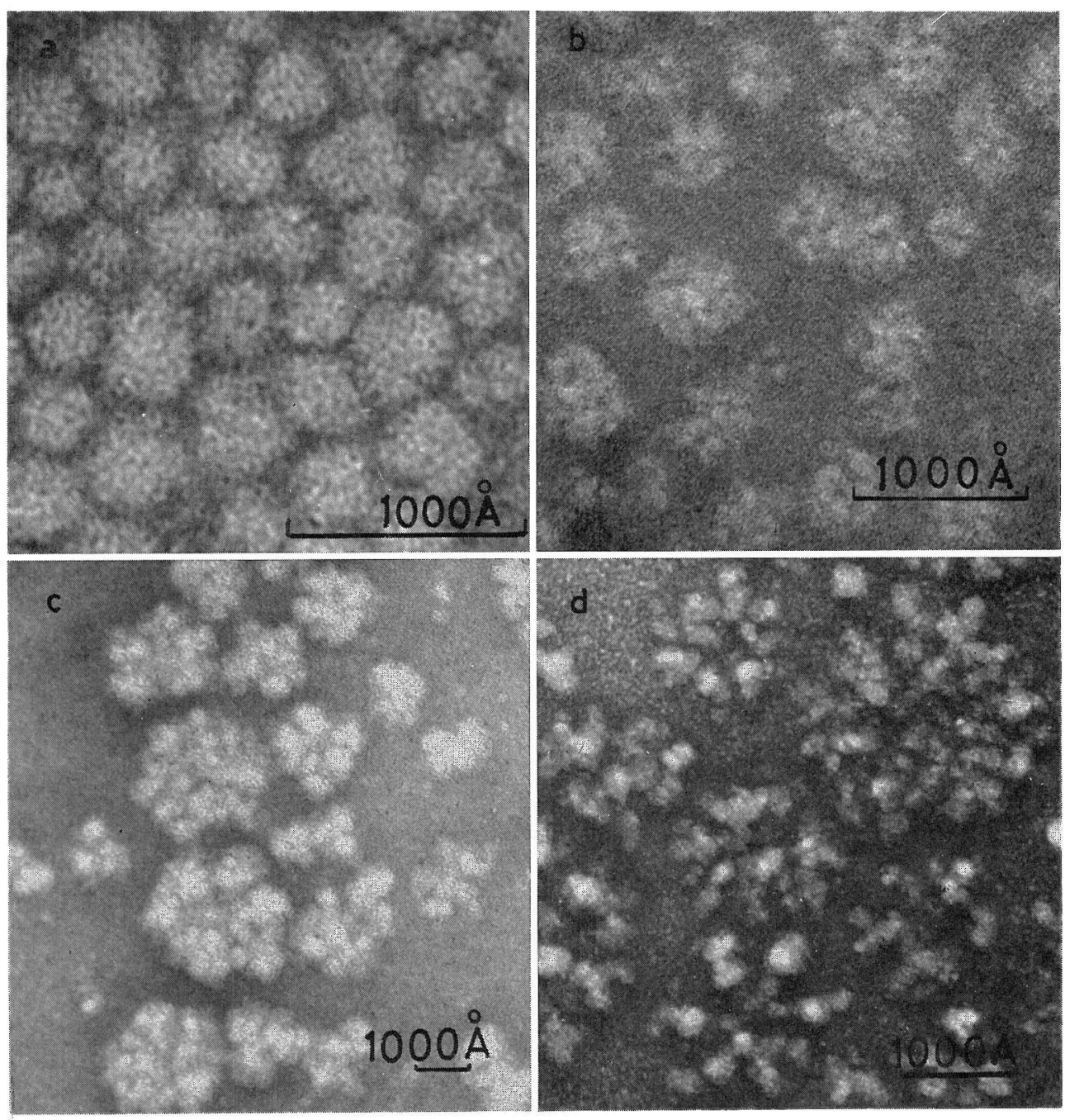

Fig. 3. Electronmicroscopic observation of glycogens

a) Muscle glycogen particles from well-fed rat b) Muscle glycogen particles from fasted rat
c) Liver glycogen particles from well-fed rat
d) Liver glycogen particles from fasted rat 
respectively. $\beta$-Amvlolysis of the liver and muscle glycogen: For the liver glycogen the degree of $\beta$-amylolysis reached to $35 \%$ in $30 \mathrm{~min}$ and finally $44.1 \%$ in 24 hours. On the other hand, the degree of $\beta$-amylolysis of the muscle glycogen reached $19 \%$ in $30 \mathrm{~min}$ and $24.6 \%$ in 24 hours (Fig. 4). These facts might result from the two stages of the reaction suggested by Lee (12).

Comparison of $\beta$-amylase limit dextrins from the liver and muscle glycogen: The $\beta$-amylase limit dextrin from the liver glycogen was more rapidly eluted than it was from the

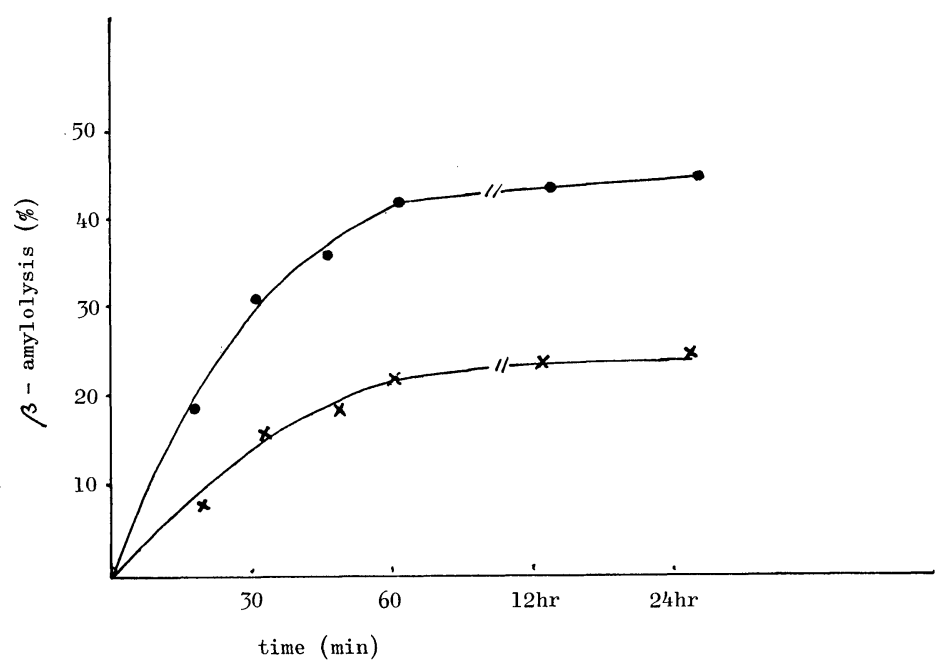

FIG. 4. Time course of the $\beta$-amylolysis of the rat liver and muscle glycogen liver glycogen $-\bullet-\bullet \quad$ muscle glycogen $-\times-\times-$

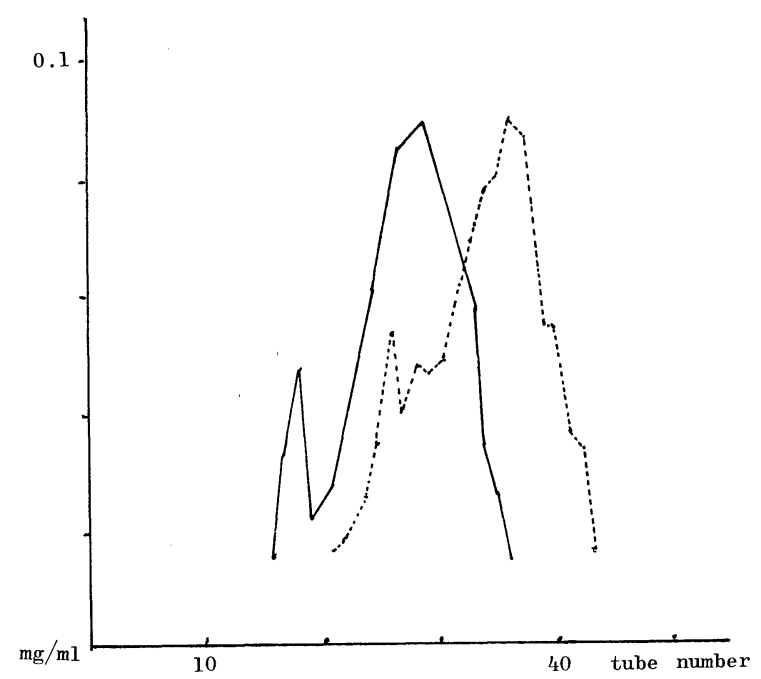

FIG. 5. Analysis of the $\beta$-amylase limit dextrin from liver and muscle glycogen _ $\beta$ limit dextrin from liver glycogen $\beta$ limit dextrin from muscle glycogen 
muscle glycogen in the sepharose $4 \mathrm{~B}$ column. It was considered that the molecular weight of the $\beta$-limit dextrin from the liver glycogen was larger than the $\beta$-limit dextrin from the muscle glycogen (Fig. 5). The average chain length and degree of $\beta$-amylolysis of the liver glycogen was larger than the muscle glycogen. Moreover, the inner structure of the liver glycogen was different from that of the muscle glycogen. According to these facts, the possibility that the high molecular weight of glycogen would be the result of a protein-bonded aggregation was not agreeable. The viscosity measurements: The viscosity related to the variation of temperature was illustrated in Fig. 6, and suggested the non-aggregated structure of glycogen.

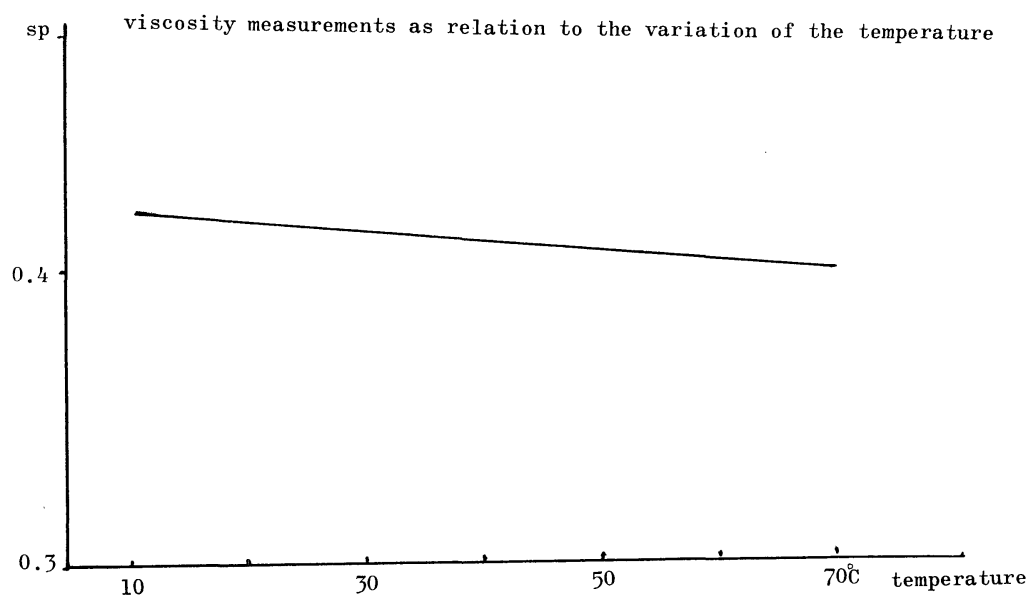

Fig. 6. sample concentration; $5 \%$ aq solution viscometer; Cannon-Menning Semi micro 50 A 302 (constant: 0.003844 centistokes/second)

0.R.D and C.D Spectra of glycogens

( adition of iodine)

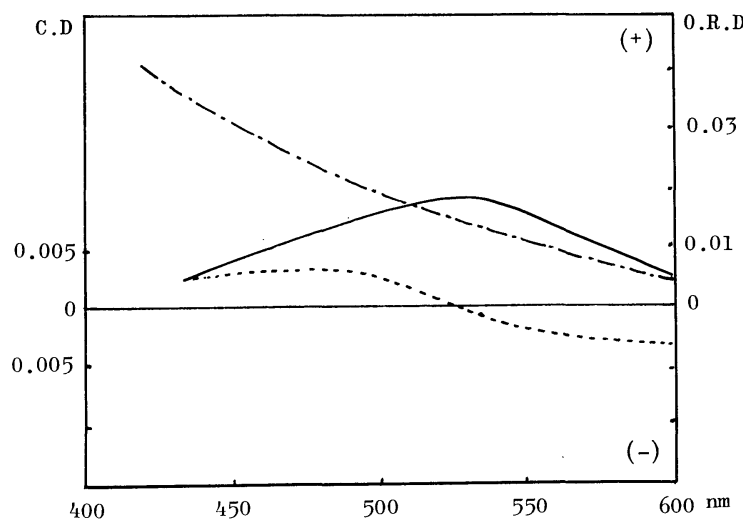

FIG. 7. sample concentration; $1 \mathrm{mg} / \mathrm{ml}$ each. solvent; distilled water to $0.5 \mathrm{ml}$ of glycogen solution, $0.01 \mathrm{~N} \mathrm{I}_{2}$ was added. cell length; $0.2 \mathrm{~cm}$. temperature; $20^{\circ} \mathrm{C}$

O.R.D; liver glycogen muscle glycogen

C.D; muscle glycogen 


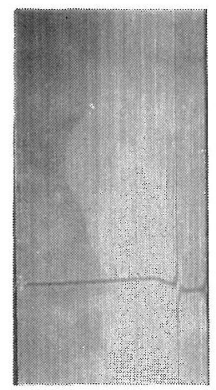

$6 \mathrm{~min}$

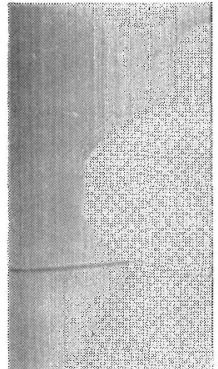

8 min

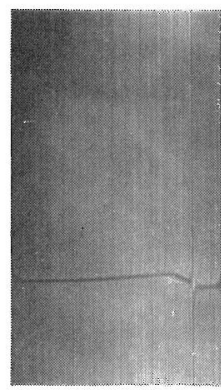

$5 \mathrm{~min}$

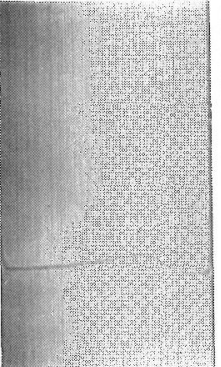

$6 \mathrm{~min}$

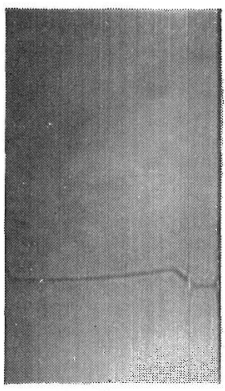

$3.10 \mathrm{~min}$

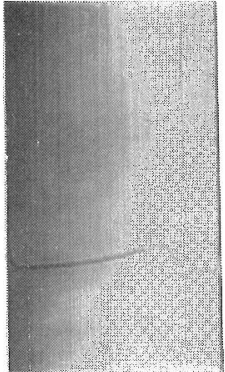

$4 \mathrm{~min}$

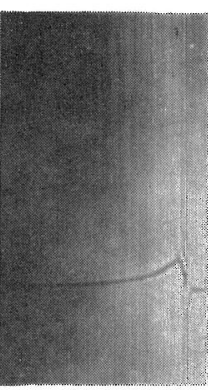

$1 \mathrm{~min}$

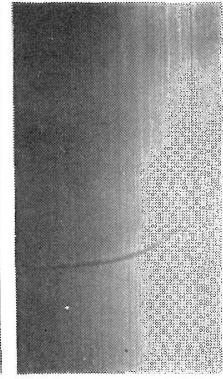

$2 \min$ sample concentration $5 \mathrm{mg} / \mathrm{ml}$ $16880 \mathrm{rpm} \quad 24^{\circ} \mathrm{C}$

$238 \mathrm{~s}$

sample concentration $10 \mathrm{mg} / \mathrm{ml}$ $16880 \mathrm{rpm} \quad 24^{\circ} \mathrm{C}$

$213 \mathrm{~s}$

FIG. 8. Sedimentation Coefficient of Liver Glycogen

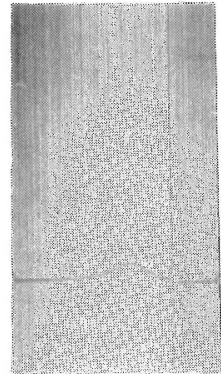

$20 \mathrm{~min}$

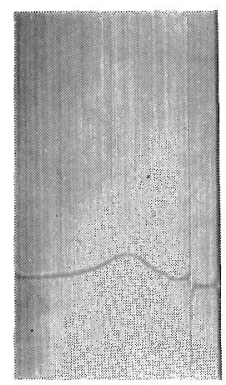

30 min

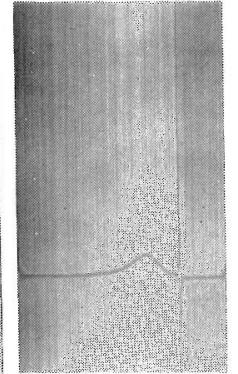

$15 \mathrm{~min}$

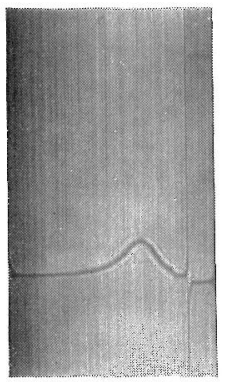

$22 \mathrm{~min}$

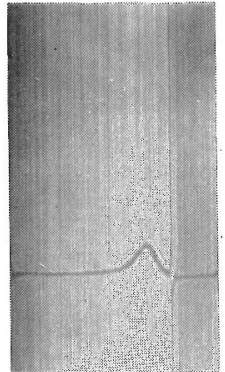

$11 \mathrm{~min}$

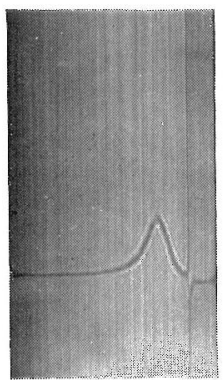

$14 \mathrm{~min}$

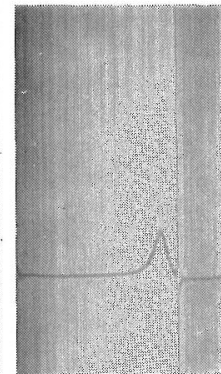

$7 \mathrm{~min}$

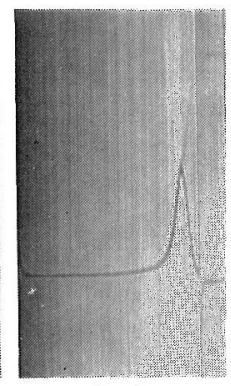

$7 \mathrm{~min}$ sample concentration

$5 \mathrm{mg} / \mathrm{ml}$

$16880 \mathrm{rpm} \quad 24^{\circ} \mathrm{C}$

$108 \mathrm{~s}$

sample concentration

$10 \mathrm{mg} / \mathrm{ml}$

$16880 \mathrm{rpm} \quad 24^{\circ} \mathrm{C}$

$97 \mathrm{~s}$

FIG. 9. Sedimentation Coefficient of Muscle Glycogen 
The measurement of $O R D$ and $C D$ waves: Only the muscle glycogen exhibited the Cotton effect on the ORD and CD waves by an addition of iodine, while the liver glycogen did not show the Cotton effect by iodine addition. The fine structure of the chain conformation was different between the liver and muscle glycogen. There was a likely possibility that the $\alpha$-glucose chains of the muscle glycogen had the stronger helix structure than the liver glycogen, or the liver glycogen was proposed to have a somewhat random coil of the chains (Fig. 7).

Analytical ultracentrifugation: The sedimentation coefficients were calculated for two of the different glycogen concentrations. At $5 \mathrm{mg} / \mathrm{ml}$ concentration, the sedimentation coefficient of the liver glycogen showed the 238s and that of the muscle glycogen was $108 \mathrm{~s}$. On the other hand, at $10 \mathrm{mg} / \mathrm{ml}$, the $s$ value for the liver glycogen was $213 \mathrm{~s}$ and it was $97 \mathrm{~s}$ for the muscle.

The sedimentation coefficient of the glycogen products was slightly decreased during the change of sample concentration from $5 \mathrm{mg} / \mathrm{ml}$ to $10 \mathrm{mg} / \mathrm{ml}$.

However, the aggregation of the glycogen molecules, or the entanglement of the chains among glycogen molecules were not suggested (Fig. 8, 9).

\section{DISCUSSION}

Iwamasa et al. proposed that the liver and muscle glycogen had a spheroidal branching bodies in structure, and would be the non-aggregated structure from their own experiments. The average chain length of the liver glycogen was longer than that of the muscle glycogen. The $\beta$-limit dextrin obtained from the liver glycogen was larger than that from the muscle glycogen in molecular size. The average chain length, the degree of $\beta$-amylolysis and $\beta$-limit dextrin from both glycogens showed the one proposal, suggesting that the liver and muscle glycogens were different polymers of $\alpha$-glucopyranose originally. It was considered, in tissue in situ, that the particulate growth of the liver and muscle glycogens was regulated by the balance of glycogenosis and glycolysis and that the high molecular weight of glycogens was not the result from the aggregation forming in the particulate growth. In fact, in my previous reports, the glycogens of high molecular weight were synthesized only by the combined actions of phosphorylase and branching glycosyltransferase. Difference between both $\beta$-limit dextrins from the liver and muscle glycogens was dependant on the different regulatory balances among those two tissues. Exactly, the viscosity measurement during variation of temperature taken in this experiment strongly supported that glycogen had a non-aggregated structure. It was considered from the results of measurements of ORD and CD spectra waves that the $\alpha-1,4$ linked chain of glycogen had a helical structure in physico-chemistry, and the helical state of muscle glycogen particle was stronger than the liver glycogen. It seems therefore, to be reasonable that the muscle glycogen particles appeared as a small branching bodies under the electron microscope. On the contrary, the liver glycogen seems to have a somewhat random coil of the $\alpha-1,4$ linked chain, and it was observed that the liver glycogen particles had the larger spheroidal branching structure under the electron microscope. From these facts resulting from the experiments, it was considered that both liver and muscle glycogens are the branched polymers of $\alpha$-glucopyranose units joined by $\alpha-1,4$ and $\alpha-1,6$ glucosidic linkages and their chemical branched structures 
presumably revealed the larger spheroidal branching and smaller branching bodies respectively. Differences between the liver and muscle glycogen demonstrated under electron microscope might be caused by their chemical structure $(6,20,21)$. Furthermore, the entanglement of the chains among glycogen molecules during centrifugation was not observed by the Schlieren diagram.

\section{REFERENCES}

1. Akai, H., Yokobayashi, K., Misaki, A. and Harada, T.: Complete hydrolysis of branching linkages in glycogen by pseudomonas isoamylase. Distribution of liner chain. Biochem. Biophys. Acta 237; 422-429, 1971.

2. Barton, A. D.: Glycogen particles in rat liver homogenates, Fed. Proc. 15; 10-11, 1956.

3. Bueding, E. and Orrel, S. A.: A mild procedure for the isolation of polydisperese glycogen from animal tissues. J. Biol. Chem. 239; 4018-4020, 1964.

4. Drochmans, P.: Morphologie du glycogene. J. Ultrastr. Res. 6; 141-163, 1962.

5. French, D.: In control of glycogen metabolism, eds. whelan. W. J. and cameron, M. P. 71964 .

6. Iwamasa, T., Fujisaki, A. and Takeuchi, T.: Ultrastructure of glycogen particles, a study from the ultrastructural and physicochemical view points. J. Electronmicr. 19; 371-380, 1970.

7. Iwamasa, T. and Takeuchi, T.: Macromolecular structure of glycogen in the rat liver and muscle. J. Electronmicr. 20; 233, 1971.

8. Iwamasa, T.: Chemical factors in the iodine coloration reaction employed in the Histochemical demonstration of phosphorylase. Acta. Histochem. Cytochem. 5; 1972 (in press).

9. Larner, J., Illingworth, B., Cori, G. T. and Cori, C. F.: Structure of glycogens and amylopectins, II. Analysis by stepwise enzymatic degradation. J. Biol. Chem. 199; 641-651, 1952.

10. Larner, J.: The action of branching enzymer on outer chains of glycogen. J. Biol. Chem. 202; 491-503, 1953.

11. Lazarow, A.: Particulate glycogen: A submicroscopic component of the guinea pig liver cell; its significance in glycogen storage and the regulation of blood sugar. Anat. Rec. 84; 31-50, 1942.

12. Lee, E. Y. C.: The action of sweet potato $\beta$-amylase on glycogen and amylopectin: Formation of a novel limit dextrin, Arch. Biochem. Biophys. 146; 488-492, 1971.

13. Liddle, A. M. and Manner, D.J.: Action of $\beta$-amylase, muscle phosphorylase and potato phosphorylase on some glycogens, Biochem. J. XII, 61; 1955.

14. Liddle, A. M. and Manner, D. J.: 682, $\alpha-1$, 4-Glucans; Part VI. Further studies on the molecular structures of glycogens. J. Chem. Soc. 3432-2436, 1957.

15. Lowry, O. H., Rosebrough, N.J., Farr, A. L. and Randull, R. J.: Protein measurement with the Folin Phenol reagent. J. Biol. Chem. 193; 265-275, 1951.

16. Meyer, K. H.: The chemistry of glycogen. Advanc. Enzymol. 3; 109-135, 1943.

17. Mordoh, J., Leloir, L. F. and Krisman, C. R.: In vitro synthesis of particulate glycogen. Proc., Nat. Acad. Sci. 53; 86-91, 1965.

18. Seifter, S., Dayton, S., Novic, B. and Muntwyler, E.: The estimation of glycogen with anthrone reagent. Arch. Biochem. Biophys. 25; 191-200, 1950.

19. Seveg, M. G.: Eine neve physikalische Enteiweissurgs-methode zur Darstellung biologisch worksamer Substanzen: Isilierung von Kohlenhydraten aus Huhnereiweiss und Pneumococcen, Biochem. Z. 273; 419-429, 1934.

20. Takeuchi, T.: Morphological Studies on the metabolism of glycogen on the basis of enzymatic reaction. Transact. Soc. Path. Jap. (Jap. Ed.) 55; 35-65, 1966.

21. Takeuchi, T. and Sasaki, M.: Histochemical and electron-micronscopic differences between native glycogen and polyglucose synthesized by phosphorylase in tissue cells. Acta. Histochem. Cytochem. 1; 63-78, 1968. 